\title{
Comparison Between, 'Loading' Dose and 'Traditional' Dose of Magnesium Sulfate for Controlling Convulsion in Eclampsia
}

Halima Khatun ${ }^{1 *}$, Md. Saiful Islam², Tarikul Islam ${ }^{3}$, Tanzila Rubaba Rahman ${ }^{4}$

\footnotetext{
${ }^{1}$ Halima Khatun, Junior Consultant, Department of Obstetrics \& Gynecology, Rajshahi Medical College Hospital, Rajshahi, Bangladesh ${ }^{2}$ Md. Saiful Islam, Associate Professor, Department of Radiology \& Imaging, Rajshahi Medical College Hospital, Rajshahi, Bangladesh

${ }^{3}$ Tarikul Islam, Assistant Professor, Department of Burn \& Plastic Surgery, Khulna Medical College Hospital, Khulna, Bangladesh

${ }^{4}$ Tanzila Rubaba RahmanLecturer, Department of Pharmacology, Khulna Medical College, Khulna, Bangladesh
}

*Corresponding author: Dr. Halima Khatun

\section{Abstract}

Original Research Article

Introduction: Eclampsia is important cause of maternal mortality during pregnancy, child birth and puerperium. It accounts for $(16 \%)$ of maternal mortality and still regarded as one of the leading cause of maternal death. In Bangladesh, eclampsia is the $3^{\text {rd }}$ major cause of maternal death. Magnesium sulfate is now the drug of choice for women with eclampsia for controlling convulsion with strong evidence that it is better than diazepam, phenytoin or lytic cocktail. Objective: To compare the effect of 'loading' dose of magnesium sulfate with that of 'traditional' dose for control of convulsion in eclampsia. Methods: Prospective comparative study. In the Department of Obstetrics and Gynaecology, Rajshahi Medical College Hospital (RMCH)" from January 08 to December, 08 Ectamptic patients with gestational periods beyond 28 weeks. A total of 100 eclamptic patients who are eligible for magnesium sulfate therapy were purposively assigned to receive either only loading "dose or traditional dose for control of convulsion. Data was organized and the results were presented in tables, figures, diagram etc by using SPSS-10 and MS-Excel 2016. Continuous variables between groups were compared by using the unpaired't' test and chi-square test and ' $\mathrm{P}$ ' Value less than 0.05 were considered statistically significant. Results: It shows that there is no significant difference between the two groups in terms of patient's profile, physical findings, distribution of convulsion along with recurrence, feto-maternal out come and regarding the toxicity of magnesium sulfate. Conclusion: The present study shows that only loading dose has some advantage over traditional dose because once loading dose is administered frequent monitoring of the patient is not necessary. So manpower involvement is less. As single loading dose can effectively control and prevent recurrent convulsion, so no extra cost" is re quired for extra $\mathrm{MgSO}_{4}$. For the above reasons eclampsia can be treated effectively by only loading dose of $\mathrm{Mgs}_{4}$ in primary as well as tertiary level hospital which will significantly reduce the maternal morbidity and mortality.

Keywords: Eclampsia, Magnesium Sulfate dose, Loading dose, Traditional dose, maternal mortality.

Copyright $\odot 2020$ The Author(s): This is an open-access article distributed under the terms of the Creative Commons Attribution 4.0 International License (CC BY-NC 4.0) which permits unrestricted use, distribution, and reproduction in any medium for non-commercial use provided the original author and source are credited

\section{INTRODUCTION}

Eclampsia is important cause of maternal mortality during pregnancy, childbirth and puerperium. Of the estimated 500,000 maternal deaths every year worldwide $10 \%$ to $15 \%$ are associated with hypertensive disorders of pregnancy [1], Eclampsia is a serious \& relatively frequent complication of pregnancy bearing a high-maternal \& perinatal mortality in our country. Eclampsia accounts for $16 \%$ of maternal mortality and still regarded as one of the leading cause of maternal death [2]. In Bangladesh, eclampsia is the $3^{\text {rd }}$ major cause of maternal death ${ }^{3}$. Eclampsia is defined as the new onset of convulsions during pregnancy or post-partum, unrelated to other cerebral pathologic conditions, in women with preeclampsia. Eclampsia is associated with significant life threatening complications, such as pulmonary oedema, renal and hepatic failure, disseminated intravascular coagulopathy and HELLP (hemolysis, elevated liver enzymes and low platelet count) syndrome. Eclampsia is also an important cause of intrauterine growth retardation, intrauterine death, still birth \& low birth weight [3]. Eclampsia is more common in young \& elderly primigravidae, patients having family history of pre-eclampsia, eclampsia $9 \mathrm{r}$ hypertension, poor or under-privileged people, patients of complicated pregnancy as in molar pregnancy, multiple pregnancy, etc. Patients having medical disorders e.g. hypertension, nephritis, diabetes mellitus etc [4]. Eclampsia is a multisystem disorder with complex pathogenesis, which is not completely understood. Cerebral involvement causing convulsions can kill the mother and fetus unless expertly managed. 
Until recently, the treatment of eclampsia varied throughout the world, though the basic principles of management such as control of convulsion, control of hypertension, initiation of steps to effect delivery and general nursing care were the same. The use of anticonvulsant varies in different parts of the world. Among the many anticonvulsants, magnesium sulfate $\left(\mathrm{MgSO}_{4}\right)$ topped the list of all in terms-of controlling convulsion and improving other secondary out comes [5]. Magnesium sulfate was first suggested in 1906 and has been popular in USA ever since. In RMCH \& many obstetric centres of Bangladesh $\mathrm{MgSO}_{4}$ has been used as a routine anticonvulsant since 1998. According to guidelines published by the Eclampsia Working Group the dose schedule is $4 \mathrm{~g}$ intravenous and $3 \mathrm{~g}$ intramuscular injection in each buttock as a loading dose, followed by $2.5 \mathrm{~g}$ intramuscularly every 4 hours in each alternate buttock until 24 hours after the last fit or delivery. During recent years, several randomized trials were reported that compared the efficacy of magnesium sulfate with other anticonvulsants in eclamptic women". Magnesium sulfate is now the drug of choice for women with eclampsia with strong evidence that it is better than diazepam, phenytoin or lytic cocktail $[6,7]$.

To the best of our knowledge, there is no established study in Rajshahi Medical College Hospital (RMCH) regarding the controlled trial of 'loading' with 'traditional' dose of magnesium, sulfate for the control of convulsion in eclampsia. Single loading dose of magnesium sulfate has many advantages like its easy administration, less complication, less man power involvement. It does not require frequent monitoring of the patient. Besides these the loading dose has some cost benefit ratio over 'traditional' dose. Therefore, the current study will be performed to establish the fact that a single 'loading' dose of magnesium sulfate is effective in controlling as well as preventing convulsion in eclampsia comparing with 'traditional' dose of magnesium sulfate.

\section{OBJECTIVES}

\section{General Objective}

- To compare, the effect of 'loading' dose of magnesium sulfate with that of 'traditional' dose for control of convulsion in eclampsia.

\section{Specific Objectives}

- To determine the effects of loading dose of $\mathrm{MgSO}_{4}$ on control of convulsion.

- To find out the effects of traditional dose (loading plus maintenance dose) on control of convulsion.

- To compare the feto-maternal out comes in both the groups.

\section{Methodology \& Materials}

This was a cross sectional experimental study and was conducted in the Department of Obstetrics \& Gynecology in Rajshahi Medical College Hospital,
Rajshahi, Bangladesh during the period January, 2008 to December, 2008. Purposive Sampling technique used for this study, then 100 eclamptic patients fulfilling the inclusion criteria were purposively included in this study. The patients were divided into two groups: Group-I: patients under this group received loading dose (10gm) of magnesium sulfate only. GroupII: patients under this group received 'traditional' dose which means loading dose plus maintenance dose (2.5 gm) for 24 hours after the last convulsion 'or delivery.

\section{Inclusion criteria}

- Eclamptic patients with gestational period beyond 28 weeks.

\section{Exclusion criteria}

- Gestational period less than 28 weeks.

- Eclamptic patients in whom magnesium sulfate therapy is contraindicated (i,e, oliguria, renal failure, absent deep tendon reflex, respiratory rate $<16 / \mathrm{m})$

- Comatose patients;

- Patients who received MgS04 from outside;

Eclamptic cases were selected from the 'Department of Obstetrics \& Gynaecology of Rajshahi Medical Collage Hospital (RMCH) during the study period was investigated. Patients who met the selection criteria of the study were identified during admission, then they were purposively assigned to receive either loading dose of MgS04 or 'traditional dose' (loading plus maintenance dose), possible effects and out comes in two groups were observed. Maternal outcomes were measured by recurrence of convulsion, time taken to control fit, time taken to regain consciousness, presence or absence of maternal complications e,g pulmonary oedema, renal failure, DIC, HELLP syndrome and maternal death. Fetal outcomes were measured by APGAR rating at birth. For all women detailed history, physical examination, necessary and available investigations were carried out. Data were collected in a predesigned structured data collection sheets. Data was organized and the results were presented in tables, figures, diagram etc by using SPSS-10 and MS-Excel 2016. Continuous variables between groups were compared by using the unpaired't' test and chi-square test and ' $\mathrm{P}$ ' Value less than 0.05 were considered statistically significant.

\section{RESULT}

The mean $( \pm$ SD) age was $25.92 \pm 5.63$ years in group I and $25.64 \pm 5.57$ years in group II. Maximum number was found in the age group of 26-30 years in both groups (Table-1). None of the patients were from the higher socioeconomic status. Sixteen percent of the patient in group I and $18.0 \%$ in group II were admitted to the hospital with term (>37 weeks) pregnancy (Table-2). The mean $( \pm \mathrm{SD})$ gestational age was $35.14 \pm 2.49$ and $3 \mathrm{~S} .16 \pm 2.33$ weeks in group I and group 
II respectively (Table-3). There was no statistical significant difference $(\mathrm{p}>0.05)$ in regards to age, parity, gestational age, socioeconomic status and type of eclampsia of the patients was found between two groups in unpaired t-test. About one third (30.0\%) patients in group I and $32.0 \%$ of the patients in group II were presented in the conscious state. It was observed that semiconscious, mild oedema $(42.0 \%$. and $44.0 \%)$ and mild urinary $(48.0 \%$ and $46.0 \%)$ albumin was predominant in the both groups. There was no statistically significant different in the two groups (Table-4). The mean $( \pm \mathrm{SD})$ number of convulsion (before admission) was $6.08 \pm 1.86$ in group I and 6.12 \pm 1.88 in group II. The mean $( \pm \mathrm{SD})$ convulsion (fit) and admission interval was $5.98 \pm 1.20$ and $5.88 \pm 1.22$ hours, in group I group II respectively. In group I, the mean
$( \pm \mathrm{SD})$ convulsion and treatment interval was $6.23 \pm 1.18$ hours and in group II was $6.19 \pm 1.22$ hours. The mean $( \pm$ SD) convulsion (fit) and delivery interval was $7.95 \pm 1.33$ in group I and $7.9 \pm 1.35$ in group II. No statistical significant $(\mathrm{p}>0.05)$ difference was found, between two groups in unpaired t-test (Table-5). Regained consciousness was predominant in the both groups about $28(56.0 \%)$ patients of the group I and $27(54.0 \%)$ in group II after initiation of treatment. Maternal death was found $1(2.00 \%)$ in group I and $2(4.0 \%)$ in group II. The cause of maternal mortality in group I was due to renal failure and group II was due to pulmonary oedema with respiratory failure. No "statistical significant $(\mathrm{p}>0.05)$ difference was found between two groups (Table-6).

Table-1: Distribute the study people according to age in two groups $(\mathrm{N}=100)$

\begin{tabular}{|l|l|l|l|l|l|}
\hline \multirow{2}{*}{ Age (Years) } & Group I $(\mathbf{n}=\mathbf{5 0})$ & \multicolumn{2}{|l|}{ Group II $(\mathbf{n = 5 0})$} & \multirow{2}{*}{ P Value } \\
\cline { 2 - 5 } & $\mathbf{n}$ & $\mathbf{\%}$ & $\mathbf{n}$ & $\mathbf{\%}$ & \\
\hline$\leq 20$ & 12 & 24.0 & 13 & 26.0 & \multirow{2}{*}{$0.803(\mathrm{NS})$} \\
\hline $21-25$ & 11 & 22.0 & 11 & 22.0 & \\
\hline $26-30$ & 17 & 34.0 & 17 & 34.0 & \\
\hline$>30$ & 10 & 20.0 & 9 & 18.0 & \\
\hline Mean \pm SD & $25.92 \pm 5.63$ & \multicolumn{2}{|l|}{$25.64 \pm 5.57$} & \\
\hline
\end{tabular}

Table-2: Distribute the two group of study people according to socio-economic status $(\mathrm{N}=100)$

\begin{tabular}{|l|l|l|l|l|}
\hline \multirow{2}{*}{ Socio-economic status } & \multicolumn{2}{|l|}{ Group I (n=50) } & \multicolumn{2}{l|}{ Group II (n=50) } \\
\cline { 2 - 5 } & $\mathbf{n}$ & $\mathbf{\%}$ & $\mathbf{n}$ & \% \\
\hline Low & 38 & 76.0 & 35 & 70.0 \\
\hline Middle & 12 & 24.0 & 15 & 30.0 \\
\hline Parity & 11 & 22.0 & 11 & 22.0 \\
\hline Primi & 17 & 34.0 & 17 & 34.0 \\
\hline Multi & 10 & 20.0 & 9 & 18.0 \\
\hline Grand multi & 3 & 6.0 & 2 & 4.0 \\
\hline
\end{tabular}

Table-3: Distribute the two groups of study people according to gastation age (wks) $(\mathrm{N}=100)$

\begin{tabular}{|l|l|l|l|l|l|}
\hline \multirow{2}{*}{ Gastation age (wks) } & \multicolumn{2}{|l|}{ Group I (n=50) } & \multicolumn{2}{|l|}{ Group II (n=50) } & \multirow{2}{*}{ P Value } \\
\cline { 2 - 5 } & $\mathbf{n}$ & $\mathbf{\%}$ & $\mathbf{n}$ & $\mathbf{\%}$ & \\
\hline$\leq 32$ & 9 & 18.0 & 7 & 14.0 & \multirow{2}{*}{$0.968(\mathrm{NS})$} \\
\hline $33-37$ & 33 & 66.0 & 34 & 68.0 & \\
\hline$>37$ & 8 & 16.0 & 9 & 18.0 & \\
\hline Mean \pm SD & $35.14 \pm 2.49$ & $35.16 \pm 2.33$ & \\
\hline
\end{tabular}

Table-4: Physical findings during admission of the study patients $(n=100)$

\begin{tabular}{|c|c|c|c|c|c|c|}
\hline \multirow{2}{*}{\multicolumn{2}{|c|}{ Physical condition }} & \multicolumn{2}{|c|}{ Group I $(n=50)$} & \multicolumn{2}{|c|}{ Group II (n=50) } & \multirow[t]{2}{*}{ P Value } \\
\hline & & $\mathbf{n}$ & $\%$ & $\mathbf{n}$ & $\%$ & \\
\hline \multirow{3}{*}{ Level of consciousness } & Conscious & 15 & 30.0 & 16 & 32.0 & \\
\hline & Semiconscious & 27 & 54.0 & 26 & 52.0 & ${ }^{\mathrm{a} 0} 0.974(\mathrm{NS})$ \\
\hline & Unconscious & 8 & 16.0 & 8 & 16.0 & \\
\hline \multirow[t]{4}{*}{ Oedema } & Nil & 6 & 12.0 & 6 & 12.0 & \\
\hline & Mild & 21 & 42.0 & 22 & 44.0 & $\begin{array}{l}\mathrm{a} 0.997(\mathrm{NS}) \\
\end{array}$ \\
\hline & Moderate & 1.9 & 38.0 & 18 & 36.0 & \\
\hline & Severe & 4 & 8.0 & 4 & 8.0 & \\
\hline \multirow[t]{4}{*}{ Urinary Albumin } & Nil & 4 & 8.0 & 5 & 10.0 & \\
\hline & Mild & 24 & 48.0 & 23 & 46.0 & ${ }^{\mathrm{a}} 0.987(\mathrm{NS})$ \\
\hline & Moderate & 20 & 40.0 & 20 & 40.0 & \\
\hline & Severe & 2 & 4.0 & 2 & 4.0 & \\
\hline Systolic blood pressure & Mean \pm SD & \multicolumn{2}{|c|}{$153.4 \pm 21.6$} & \multicolumn{2}{|c|}{$153.0 \pm 21.5$} & ${ }^{\mathrm{b}} 0.926(\mathrm{NS})$ \\
\hline Diastolic blood pressure & Mean \pm SD & \multicolumn{2}{|c|}{$105.0 \pm 14.4$} & \multicolumn{2}{|c|}{$104.6 \pm 14.2$} & ${ }^{\mathrm{b}} 0.889(\mathrm{NS})$ \\
\hline
\end{tabular}

Table-5: Comparison of distribution of convulsion before and after treatment of eclampsia ( $\mathrm{N}=100)$

$$
\begin{array}{|l|l|l|}
\text { Group I (n=50) } & \text { Group II }(\mathbf{n}=50) & \text { P Value } \\
\hline
\end{array}
$$


Halima Khatun et al; Sch J App Med Sci, Dec, 2020; 8(12): 2834-2839

\begin{tabular}{|l|l|l|l|}
\hline & Mean \pm SD & Mean \pm SD & \\
\hline No of convulsion (before admission) & $6.08 \pm 1.86$ & $6.12 \pm 1.88$ & $0.915(\mathrm{NS})$ \\
\hline Convulsion(fit)and admission interval & $5.98 \pm 1.2$ & $5.88 \pm 1.22$ & $0.681(\mathrm{NS})$ \\
\hline Convulsion and treatment interval & $6.23 \pm 1.18$ & $6.19 \pm 1.22$ & $0.875(\mathrm{NS})$ \\
\hline Convulsion (fit) and delivery interval & $7.95 \pm 1.33$ & $7.9 \pm 1.35$ & $0.858(\mathrm{NS})$ \\
\hline
\end{tabular}

Table-6: Maternal outcome after treatment of eclampsia (N=100)

\begin{tabular}{|c|c|c|c|c|c|c|}
\hline \multirow{2}{*}{\multicolumn{2}{|c|}{ Maternal outcome after treatment }} & \multicolumn{2}{|c|}{ Group I $(n=50)$} & \multicolumn{2}{|c|}{ Group II $(n=50)$} & \multirow[t]{2}{*}{ P Value } \\
\hline & & $\mathbf{n}$ & $\%$ & $\mathbf{n}$ & $\%$ & \\
\hline \multirow[t]{3}{*}{ State of consciousness } & Remained consciousness & 20 & 40.0 & 21 & 42.0 & \multirow[t]{3}{*}{$0.978(\mathrm{NS})$} \\
\hline & Remained unconsciousness & 2 & 4.0 & 2 & 4.0 & \\
\hline & Regained consciousness & 28 & 56.0 & 27 & 54.0 & \\
\hline \multirow[t]{2}{*}{ Maternal death/Mortality } & 1 & 49 & 98.0 & 48 & 96.0 & \multirow[t]{2}{*}{$0.500(\mathrm{NS})$} \\
\hline & 2 & 1 & 2.0 & 2 & 4.0 & \\
\hline \multirow[t]{2}{*}{ Morbidity } & 1 hour & 16 & 32.0 & 17 & 34.0 & \multirow[t]{2}{*}{$0.831(\mathrm{NS})$} \\
\hline & 2 hour & 34 & 68.0 & 33 & 66.0 & \\
\hline
\end{tabular}

\section{DiscuSSION}

Eclampsia is a multi-system disorder with complex pathogenesis, which is not completely understood [5]. Control of convulsion and prevention of recurrence is one of the most. important part of management of eclampsia. There is no conclusive evidence that the best available treatment for women who have had an eclamptic fit is magnesium sulfate. Bangladesh is a developing country where the incidence of eclampsia is very high, and. eclampsia remains the leading cause of death in large tertiary level hospitals, like Rajshahi Medical College Hospital (RMCH) for many years [8]. $\mathrm{MgSO}_{4}$ has been used as a routine anticonsultant in many obstetric centers of Bangladesh since 1998. But the dose that is recommended by Bangladesh Eclampsia Working Group is much lower than that used in the Eclampsia Collaborative Trial (10 gm loading dose compared to $14 \mathrm{gm} \& 2.5 \mathrm{gm}$ instead of $5 \mathrm{gm}$ as maintenance dose) [2], The lower dose is chosen considering the smaller size for "the Bangladeshi women and concerns about toxicity in circumstances which measuring serum magnesium levels would be difficult [9]. Its efficacy in controlling convulsions and preventing recurrences has been established in many prospective studies [10]. Recently it has also been suggested that -an initial loading dose of $\mathrm{MgSO}_{4}$ is sufficient to arrest convulsion [5]. $\mathrm{MgSO}_{4}$ is not an innocuous drug. Its therapeutic \& toxic dose is very close. It is necessary to monitor the patients who are receiving the medication to prevent serious sideeffects. Duley [11] recommended frequent (every 5 to 10 minutes) monitoring during the first two hours of intravenous regimen. But the low dose (Dhaka) regimen that is being used in Bangladesh has been found to be associated with serum levels that are well below the toxic levels [10].

This cross sectional experimental study was carried out with an aim to compare the effect of loading dose of magnesium sulfate with that of traditional dose for control of convulsion in eclamsia, determine the effects of loading dose of $\mathrm{MgSO}_{4}$ and loading plus maintenance dose on control of convulsion, compare the feto-maternal out comes, side effects of magnesium sulfate and cost benefit ratio in both the groups. The mean $( \pm \mathrm{SD})$ age was $25.92 \pm 5.63$ years in group I and $25.64 \pm 5.57$ years in group II. Maximum number was found in the age group of 26-30 years in both groups. None of the patients were from the higher socioeconomic status. Sixteen percent of the patient in group I and $18.0 \%$ in group II were admitted to the hospital with term (>37 weeks) pregnancy. The mean $( \pm$ SD) gestational age was $35.14 \pm 2.49$ and $3 \mathrm{~S} .16 \pm 2.33$ weeks in group I and group II respectively, which is identical with Begum et al., [5]. There was no statistical significant difference $(p>0.05)$ in regards to age, parity, gestational age, socioeconomic status and type of eclampsia of the patients was found between two groups in unpaired t-test. As regards to the parity, Begum et al., 2001, Tailor et al., 1998 and Fleischer et al., 1991 found consistent findings in their studies, where the present study it was observed that no statistical significant difference $(p>0.05)$ of the patients was found between two groups in parity. About one third $(30.0 \%)$ patients in group I and $32.0 \%$ of the patients in group II were presented in the conscious state. It was observed that semiconscious, mild oedema $(42.0 \%$. and $44.0 \%)$ and mild urinary $(48.0 \%$ and $46.0 \%)$ albumin was predominant in the both groups. There was no statistically significant different in the two groups, which is consistent with Begum et al., [5]. The mean blood pressure was $105.0 \pm 14.4 \mathrm{mmHg}$ and $104.6 \pm 14.2 \mathrm{mmHg}$ in group I and group II respectively which is also statistically not significant ( $p>0.05)$ between two groups. The mean $( \pm \mathrm{SD})$ number of convulsion (before admission) was $6.08 \pm 1.86$ in group I and $6.12 \pm 1.88$ in group II. The mean $( \pm \mathrm{SD})$ convulsion (fit) and admission interval was $5.98 \pm 1.20$ and $5.88 \pm 1.22$ hours, in group I group II respectively. In group I, the mean $( \pm \mathrm{SD})$ convulsion and treatment interval was $6.23 \pm 1.18$ hours and in group II was $6.19 \pm 1.22$ hours. The mean $( \pm \mathrm{SD})$ convulsion (fit) and delivery interval was $7.95 \pm 1.33$ in group I and 7.9 \pm 1.35 in group II. No statistical significant $(\mathrm{p}>0.05)$ difference was -found, between two groups in unpaired t-test. Although $\mathrm{MgSO}_{4}$ is a potent anti-convulsant, in many occasions convulsion recurs. The result of collaborative Eclampsia Trial shows recurrent- 
convulsion rate $13.2 \%$ ) and $5.7 \%$ in two controlled trials [4]. From different studies it has been found that recurrent convulsion is not high in our population. Phuapradit et al., [12] found that mean serum magnesium leve1s were significantly lower in women having a weight of $>70 \mathrm{Kg}$ then the level observed in patients with a body weight $<70 \mathrm{Kg}$. after a loading dose, the drug is distributed throughout the body specially in skeletal tissues and only a small amount is left in the extracellular fluid. So the patients having lower body volume will have a higher serum drug concentration during treatment with the "maintenance regime35. Bangladeshi women are usually lighter and mean body weight of pregnant women is $53 \mathrm{Kg}$ [13]. This may explain the low rates of recurrent convulsion during MgS04 therapy. Prichard and coworkers described repeated recurrent convulsions in two women having prepregnancy weight of $130 \& 180 \mathrm{Kg}$ respectively". In this study, patients, who had recurrent convulsions, were not obese and their blood pressure was also not high at the time of convulsion. Convulsion was controlled by an additional dose of $2.5 \mathrm{gm}$ of $\mathrm{MgS} 04$. Regained consciousness was predominant in the both groups about 28(56.0\%) patients of the group I and $27(54.0 \%)$ in group II after initiation of treatment, which is commonest complications in eclamptic patients supported by the Khan [14]. Maternal death was found $1(2.00 / 0)$ in group I and 2(4.0\%) in group II. The cause of maternal mortality in group I was due to renal failure and group II was due to pulmonary oedema with respiratory failure. No "statistical significant $(\mathrm{p}>0.05)$ difference was found between two groups, which is commonest complications in eclamptic patients supported by the Khan [14]. Begum et al., [5] and Anwara [5], where they' found $4.45 \%$ and $5.02 \%$ in group I and group II respectively and $2.0 \%$ in group I and $4.0 \%$ in group II.

\section{Limitations of THE STUdy}

Our study wasn't a blinded study so patient bias was present along with observer bias in subjective recording and the limited number of patients, so it is difficult to find out overall significant result. Different types of essential investigations were difficult to do on emergency basis due to lack of investigation facilities. As the serum magnesium level estimation is a very costly and sophisticated test, we did not do this test and mostly, we had to depend on clinical monitoring.

\section{Conclusion and Recommendations}

In spite of the different preventive approaches to improve obstetrics care in Bangladesh, eclampsia is still responsible for $16 \%$ of the maternal mortality on as national basis. As the cause and pathogenesis of preeclampsia and eclampsia are still not well understood, any specific preventive or curative measures have yet not been possible. As eclampsia is primarily a convulsive state, present management of eclampsia aims to stop and control the recurrence of convulsion first. The effectiveness of the MgS04 in preventing convulsion is well studied and remarkable. $\mathrm{MgS04}$ is used only in some tertiary centers like medical colleges by the previous standard regimen. The present study shows that only loading dose has some advantage over the standard regimen. Once loading dose is administered, frequent monitoring of the patient is not necessary, unlike that of the standard regimen. So, manpower involvement is less, and as single loading dose can effectively control and prevent recurrent convulsion, patient need not. pay money for the extra amount of $\mathrm{MgSO}_{4}$. For the above reasons, eclampsia can be treated by only loading dose of $\mathrm{MgS04}$ in primary healthcare centers or before referral to a tertiary hospital. This early intervention will significantly reduce the maternal morbidity and mortality. Finally, we would like to recommend the following measures for the prevention and treatment of eclampsia: A national health programme and action plan to' improve and easy access of health facilities (like antenatal care). Establish a protocol of therapy rationale for the eclamptic patients in all healthcare levels, especially $\mathrm{MgSO}_{4}$. $\mathrm{MgSO}_{4}$ must be made easily available at government level and should be available in government hospitals. Training of healthy personnel in rural areas. Establishment of a fast referral system. Increase awareness among general population about the dreadful disease, eclampsia and its early treatment.

\section{REFERENCES}

1. Patrik FW, Khan KS, Arnott N. Magnesium sulfate in the treatment of eclampsia and preeclampsia: an overview of the evidence from randomized trials. $\mathrm{Br} \mathrm{J}$ obstet Gynaccoc, 1996; 103: 1085-1091.

2. Eclampsia Working Group, Eclampsia in Bangladesh. A review \& guideline. Bangladesh Journal of obstetrics and Gynaecology. 1997; 12:1-27.

3. Mattar F, Sibai BM. EclampsiaVIII. Risk factors for maternal morbidity. American journal of obstetrics and gynecology. 2000 Feb 1;182(2):307-12.

4. The Eclampsia Trial Collaborative Group, which anticonvulsant for at women with eclampsia? Evidence from the collaborative Eclampsia Trial. The Lancet. 1995 Jun 10;345(8963):1455-63.

5. Begum MR, Begum A, Quadir E. Loading' dose versus standard regime of magnesium sulfate in the management of eclamsia: A randomized trial. Obstet Gyneeco, 2002; 28:154-159.

6. The Magpie Trial collaborative Group, Do women with preeclampsia, and their babies, benefit from magnesium sulfate? The Magpie trial: a' randomized placebo controlled trial.' The Lancet, 2002; 359:1877-1890.

7. Lucas MJ, Lexeno KJ, Cunningham FG. A comparison of magnesium sulfate with phenytion for the prevention of EclampSia. The new England Journal of Medicine, 1995; 333:201-205. 
8. Hospital Statistics, Rajshahi Medical College Hospital. Rajshahi, Bangladesh.

9. Begum R, Begum A, Johanson R, Ali MN, Akhter S. A low dose ('Dhaka') magnesium sulfate regime for eclampsia, Acta obstet Gynecol Scand, 2001; 80:998-1002.

10. Rouf S, Shamsudin L, Khan JH. Magnesium sulfate versus diazepam in the management of eclampsia. Bangladesh J Obstet Gyneco, 1996; 11:1-14.

11. Chien PF, Khan KS, Arnott N. Magnesium sulphate in the treatment of eclampsia and preeclampsia: an overview of the evidence from randomised trials. BJOG: An International Journal of Obstetrics \& Gynaecology. 1996 Nov;103(11):1085-91.

12. Phuapradit W, Saropala N, Haruvasin S, Thuvasethakul P. Serum level of magnesium attained in magnesium sulfate therapy for severe preeclampsia. Asia- Oceania Journal of Obstetrics and Gynaecology. 1993 Dec;19(4):387-90.

13. Begum R, Bhuiya AB, Tahera S. Incidence of low birth weight baby in Dhaka Medical College and Hospital. Bangladesh an Obstet Gynaeco, 1995; 10:26-37.

14. Khan JH. MgS04 vs diazepam in the management of eclampsia (Dissertation) Dhaka. Bangladesh College of Physicians and surgeons. 